\title{
Concise Commentary: Gluten-Free Diets-You've Gotta Believe in Something
}

\author{
Dario Conte ${ }^{1} \cdot$ Luca Elli $^{1}$
}

Published online: 14 March 2018

○) Springer Science+Business Media, LLC, part of Springer Nature 2018

Celiac disease (CD) is an autoimmune disease primarily affecting the small intestinal mucosa that mainly manifests as malabsorption and can be accompanied by numerous inflammatory and neoplastic conditions. The observation that the disease regresses with withdrawal of dietary gluten, in addition to data obtained from extensive basic investigations, strongly supports that an immunological reaction to gluten as the primary environmental disease triggers [1]. The actual prevalence of CD in the USA and other Western nations is $\sim 1 \%$ (i.e., 3 million Americans) [2]. In recent years, a new entity termed non-celiac gluten sensitivity (NCGS) has been introduced, which, although characterized by symptoms that are reported to be related to the ingestion of gluten, is not $\mathrm{CD}$. The prevalence of NCGS according to self-reported gluten avoidance studies is $0.5-13 \%$ of the general population $[3,4]$.

In this issue of Digestive Diseases and Sciences, Rabinowitz et al. [5] evaluated patients with CD and with NCGS, reporting their beliefs concerning the effects of gluten on health status, the safety of vaccines, and the influence of gluten-free (GF) food products on overall well-being. The authors conducted a web-based survey; the questionnaire was completed by 1886 out of 8406 subjects (i.e., $27 \%$ ), of whom 217 stated that they had with NCGS, whereas 1291 were diagnosed with $\mathrm{CD}$, with otherwise comparable characteristics [4]. The data provided by the CD and NCGS participants were compared by using multivariate analysis. Interestingly as shown in summary table (condensed from tables 1-3 of the Rabinowitz paper [Table 1]), the subset of subjects with NCGS differed significantly from CD patients with regard to six items. A minority of participants $(\sim 7$ to $25 \%$ ) did not believe information provided by established resources such as the US Food and Drug Administration, international professional gastroenterological societies, or nonprofit patient-centered celiac societies. A striking $30-35 \%$ of both groups rated online sources as the most reliable.

Overall, the paper further emphasizes the disparate beliefs of CD patients and of NCGS participants, the latter possibly with an a priori opposition to information derived from research conducted by the medical establishment [6]. Of interest, the authors correctly underscore the negative economic aspects of following a GFD due to its higher costs and to its possible medical ill effects if taken outside of a supervised medical setting, and also highlight the possible dire public health consequences of vaccine avoidance [7, 8].

Luca Elli

luca.elli@policlinico.mi.it

1 Center for Prevention and Diagnosis of Celiac Disease,

Fondazione IRCCS Ca' Granda Ospedale Maggiore

Policlinico, Via F. Sforza 35, 20122 Milan, Italy 
Table 1 (Adapted from [5])

\begin{tabular}{lllll}
\hline Question & Answer & NCGS (\%) & CD (\%) & $p$ \\
\hline Are vaccines safe for CD pts? & No & 41.3 & 26.4 & .0001 \\
Are you refusing vaccination? & Yes & 30.9 & 24.2 & .007 \\
Are you refusing GMO foods? & Yes & 47.0 & 27.8 & .0001 \\
Is your diet based only on organic products? & Yes & 28.6 & 12.2 & .0001 \\
Is a gluten bad for everyone? & Yes & 31.3 & 16.3 & .0001 \\
Is GFD improving energy and concentration? & Yes & 40.3 & 20.7 & .0001 \\
\hline
\end{tabular}

\section{References}

1. Green PH, Lebwohl B, Greywoode R. Celiac disease. J Allergy Clin Immunol. 2015;135:1099-1106.

2. Rubio-Tapia A, Ludvigsson JF, Brantner TL, Murray JA, Everhart JE. The prevalence of celiac disease in the United States. Am J Gastroenterol. 2012;107:1538-1544. (quiz 1537, 1545).

3. Lebwohl B, Ludvigsson JF, Green PH. Celiac disease and nonceliac gluten sensitivity. BMJ. 2015;351:h4347.

4. Choung RS, Unalp-Arida A, Ruhl CE, Brantner TL, Everhart JE, Murray JA. Less hidden celiac disease but increased gluten avoidance without a diagnosis in the United States: findings from the National Health and Nutrition Examination Surveys from 2009 to 2014. In: Mayo Clinic Proceedings 2016.
5. Rabinowitz LG, Zylberberg HM, Levinovitz A, Stockwell MS, Green PHR, Lebwohl B. Skepticism regarding vaccine and glutenfree food safety among celiac disease and non-celiac gluten sensitivity patients. Dig Dis Sci. (Epub ahead of print). https://doi. org/10.1007/s10620-017-4879-1.

6. Tavakkoli A, Lewis SK, Tennyson CA, Lebwohl B, Green PH. Characteristics of patients who avoid wheat and/or gluten in the absence of celiac disease. Dig Dis Sci. 2014;59:1255-1261. https ://doi.org/10.1007/s10620-013-2981-6.

7. Lee AR, Ng DL, Zivin J, Green PH. Economic burden of a glutenfree diet. J Hum Nutr Diet. 2007;20:423-430.

8. Dubè E, Vivion M, MacDonald NE. Vaccine hesitancy, vaccine refusal and the anti-vaccine movement: influence, impact and implications. Expert Rev Vaccines. 2015;14:99-117. 